\title{
MODEL TESTS FOR SHALLOW-WATER SHIP MANEUVERABILITY IN THREE GORGES RESERVOIR
}

\author{
Chuang Cai, Xinyong Cai, Yi Li \\ School of River and Ocean Engineering, Chongqing Jiaotong University \\ China
}

\begin{abstract}
This paper conducts calibration tests on the shallow-water maneuverability of 1:100 ship models for the typical navigation fleets in Three Gorges Reservoir. Major influential factors for the maneuverability similitude between models and prototypes and for scale effect were identified. A correction method for model scale was also established through model tests. Test results indicate that, by correcting the model scales of various fleets based on scale effect, the maneuverability indexes K' (dimensionless of K) and T' (dimensionless of T) of ship models are suitable for shallowwater tests, and properly reflect the maneuvering characteristics of prototypes. The findings provide an experimental basis for the navigation safety in Three Gorges Reservoir.
\end{abstract}

Keywords: shallow-water test of ship model, simulated computation, maneuverability calibration, scale effect, Z shape test, $\mathrm{K}$ and T

indexes, navigation safety

\section{INTRODUCTION}

The Yangtze River Three Gorges Hydro Project navigation ship fleet model with a 1:100 scale is made for studying a series of navigation problem of Three Gorges Project, the scale of ship model is in line with normal hydraulic model. Before the test, ship model maneuverability calibration must consult the actual ship, maneuverability similarity of ship model and actual ship is found, and maneuverability need to be corrected properly, made ship model test have actual ship navigation feature, to ensure ship fleet navigation safety [8].Ship fleet is $2640 \mathrm{HP}$, respectively pushing 3, 6 and 9 kilotons covered barge, make up three different times ship fleets: recent, late and forward.

Test of ship model and hydraulic model is based on gravity similar rule. Because Re is different, maneuverability of ship model is different from actual ship. It is defined as maneuverability scale effect. In order to ensure maneuverability similarity of ship model and actual ship, ship model scale effect is needed to be corrected.

In order to study maneuverability similarity of ship model and actual ship, the shallow water test focuses on the depth similar to navigation channel of Three Gorges Project.

\section{ACTUAL SHIP INFORMATION IN GENERAL}

China the Yangtze shipping science institute has done actual ship hydrostatic maneuverability test in Poyang lake of Jiangxi province, relevant ship fleet K', T'value in (Tab.1). According to the existing ship, combine the recent shipbuilding plan, the ship fleet is selected as Three Gorges Project standard navigation ship fleet [2]. The recent is $2640 \mathrm{HP}+3 \times 1000 \mathrm{t}$ pusher barge ship fleet, trial speed is $4.289 \mathrm{~m} / \mathrm{s}$; The late is $2640 \mathrm{HP}+6 \times 1000 \mathrm{t}$ pusher barge ship fleet, trial speed is $3.567 \mathrm{~m} / \mathrm{s}$; The forward is $2640 \mathrm{HP}+9 \times 1000 \mathrm{t}$ pusher barge ship fleet, trial speed is 3.15 $\mathrm{m} / \mathrm{s}$. The above three formations must be 100,150 , and $200 \mathrm{Z}$ shape experiment. Actual ship report suggested that calibration prototype data of three ship fleet models' $Z$ shape experiment was based on 150 rudder angle K', T' value. According to test requirement, this ship model maneuverability calibration test focuses on two ship model formations: $3 \times 1000 \mathrm{t}$ and $9 \times 1000$ $\mathrm{t}$ (Fig.1).The ship fleet standard hydrostatic navigation speed is the average value of every ship formation.

\section{SHIP MODEL TEST IN GENERAL}

Test model: According to geometric similarity, ship is made of glass fiber reinforced plastics, step-less steering remote control, transform speed, test camera with beat flash and laser scanning are installed.

Test basin: Built in a closed trial hall, the test is not affected by outside wind and highlight. The size is $42 \mathrm{~m} \times 13.5 \mathrm{~m} \times 1.4$ 
$\mathrm{m}$, the depth of water can adjust in a range of $0 \mathrm{~m}$ and $1.4 \mathrm{~m}$, flatness error of the bottom is less than $\pm 1 \mathrm{~mm}$, it can be used as ship model shallow water test.

Tab. 1. Actual k', $t^{\prime}$ Index and Trial Speed

\begin{tabular}{|c|c|c|c|c|}
\hline 岕 & $\begin{array}{c}\text { Rudder } \\
\text { Angle }\left(^{\circ}\right)\end{array}$ & 3 Barges & 6 Barges & 9 Barges \\
\hline \multirow{3}{*}{$\mathrm{K}^{\prime}$} & 10 & 2.050 & 1.775 & 1.715 \\
\hline & 15 & 1.680 & 1.640 & 1.540 \\
\hline & 20 & 1.590 & 1.460 & 1.340 \\
\hline \multirow{3}{*}{$\mathrm{T}^{\prime}$} & 10 & 0.998 & 0.780 & 0.773 \\
\hline & 15 & 0.695 & 0.653 & 0.640 \\
\hline & 20 & 0.681 & 0.626 & 0.429 \\
\hline \multicolumn{2}{|c|}{ trial speed $(\mathrm{m} / \mathrm{s})$} & 4.289 & 3.567 & 3.155 \\
\hline
\end{tabular}

(a)

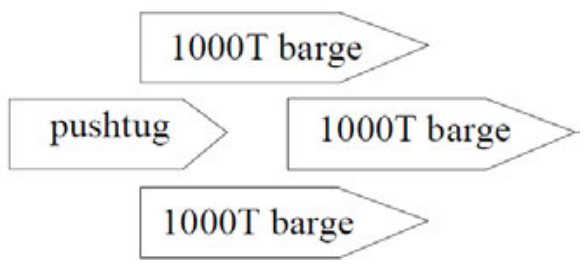

(b)

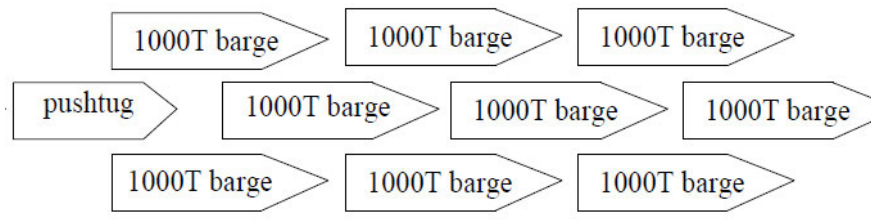

Fig. 1. Ship model maneuverability calibration test fleets (a. Recent navigation $3000 t$ ship model fleet with a scale 1:100; $b$. Recent navigation 9000t ship model fleet with a scale 1:100)
Test system: Test uses CMZ-3B ship model automatic test system. The test system can non-contact rapidly scan ship model movement by using laser scanning instrument, computer will realize real-time telemeter, control and compute for operation posture and maneuverability element of ship model, test will happen automatically. It is able to do the test of ship model sailing, $Z$ shape and turning, and watch the dynamic process after test [1].

\section{TEST METHOD}

The channel of Three Gorges Project is narrow and changeful; ship fleet is mainly sail with frequent small rudder angle, so it meets the actual circs better for analyzing maneuverability of navigation ship model by Z shape test. Before the test, ship model is adjusted for straight course, trail speed was set. When reaches to the specific conditions of test, begin to steer first rudder, CMZ-3B system will finish the whole process of calibration test. Computer can provide real-time process curve, and watch sailing dynamic process from digital display window. After the test, CMZ-3B system can work rapidly data processing, real-timely output every maneuverability parameter, and draw process related diagrams.

\section{COMPUTATIONAL METHOD}

The analysis and computation of ship model maneuverability test date is on the basis of ship linear first-order maneuverability movement differential equation [5-8].The Equation as follows:

$$
\mathrm{Td} \dot{\theta} / \mathrm{dt}+\dot{\theta}=\mathrm{K} \delta
$$

Where: $\theta=$ rotary angular velocity; $\mathrm{t}=$ time; $\delta=$ rudder angle; $\mathrm{K}=$ revolving index; $\mathrm{T}$ = steering quality index.

First according to telemetry data, we can obtain relationship of Time $(\mathrm{t})$, Heading angle $(\theta)$ and Rudder angle $(\delta)$, draw procedure chart $\theta$-t, $\delta$-t. In the chart $\theta$-t, $\delta$-t, characteristic parameter of different period of times into Equation (1), compose simultaneous differential equations, ship maneuverability index $\mathrm{K}$, T and normalized index K', T', facilitates comparison of ship model and actual ship.

Analysis and calculation process of $\mathrm{K}, \mathrm{T}$ as follows:

$\delta=0$, ship cannot directly sail under water flow influence of outside conditions, constant modifications $\delta_{\gamma}$ need to be taken into account $\delta_{r}$, first-order Equation (1) can be given

Tab. 2. Ship Model Z Shape Test Result (15²udder Angle)

\begin{tabular}{|c|c|c|c|c|c|c|}
\hline & & Dudder A roo & & & & \\
\hline & Fleet & (\%) & Numprical Value & Error & Numorical Value & Error \\
\hline Actural & 9 Barges & 100 & 1.540 & & 0.640 & \\
\hline Actuda & 3 Barges & 100 & 1.680 & & 0.695 & \\
\hline & & 100 & 1.408 & -8.57 & 0.564 & -11.88 \\
\hline Model & 9 Barges & 80 & 1.371 & -10.97 & 0.646 & +0.94 \\
\hline Mioder & 3 Barges & 100 & 1.498 & -10.83 & 0.638 & -8.20 \\
\hline & 3 barges & 80 & 1.451 & -13.63 & 0.716 & +3.02 \\
\hline
\end{tabular}


as follows:

$$
\operatorname{Td} \dot{\theta} / d t+\dot{\theta}=K\left(\delta+\delta_{\gamma}\right)
$$

$\mathrm{t}(0, \mathrm{t})$ integrate Equation (2)

$$
T \dot{\theta}+\theta=K \delta_{\gamma} t+K \int_{0}^{t} \delta(t) d t
$$

When: $\theta$ reaches to maximum, put $t=\left(t_{e}, t_{e}^{\prime}, t_{e}^{\prime \prime}\right)$ separately into Equation (3) now angular velocity $\dot{\theta}=\left(\dot{\theta}_{e}, \dot{\theta}_{e}^{\prime}, \dot{\theta}_{e}^{\prime \prime}\right)$ tend to be 0 . We can obtain:

$$
\begin{aligned}
& \theta_{e}=K \int_{0}^{t_{e}} \delta(t) d t+K \delta_{\gamma} t_{e} \\
& \theta_{e}^{\prime}=K \int_{0}^{t_{e}^{\prime}} \delta(t) d t+K \delta_{\gamma} t_{e}^{\prime} \\
& \theta_{e}^{\prime \prime}=K \int_{0}^{t_{e}^{t_{e}}} \delta(t) d t+K \delta_{\gamma} t_{e}^{\prime \prime}
\end{aligned}
$$

$\mathrm{K}, \delta_{\gamma}$ can be found by Equation (5) and Equation (6), put $\delta_{\gamma}$ into Equation (4), obtains $\mathrm{K}$, defined as $\mathrm{K}_{4}$. Integrate $\mathrm{t}_{2} \rightarrow \mathrm{t}_{\mathrm{e}}$ interval into Equation (3) become to:

$$
T\left(\dot{\theta}_{2}-\dot{\theta}_{0}\right)=\theta_{e}-\theta_{2}-K \int_{t_{2}}^{t_{e}} \delta d t-K \delta_{r}\left(t_{e}-t_{0}\right)
$$

Plug $\mathrm{K}_{4}, \delta_{\gamma}$ in Equation (7), obtain $\mathrm{T}_{4}, \mathrm{~T}_{6}, \mathrm{~T}_{8}$ can be deduced by analogy.

In order to facilitate comparison of ship model and actual ship normalized $\mathrm{K}, \mathrm{T}$ :

$$
K^{\prime}=K \cdot \frac{L}{V_{s}}, T^{\prime}=T \cdot \frac{V_{s}}{L}
$$

Ship maneuverability index $K, T$, eliminate the effect of scale and velocity, can directly compare the maneuverability similarity of actual ship with model under various conditions. Revolution index $\mathrm{K}$ is large, shows revolution is good, steady turning radius is small; Steering quality index T is small, shows stability is good, steerage is good.

The analysis of model and actual ship maneuverability index $\mathrm{K}$ ', T' is found by using the above method, (Tab. 2) shows the result.

\section{SHIP MODEL TEST SCALE EFFECT AND CORRECTION}

Ship resistance is divided into residual resistance and friction resistance [10], residual resistance relative to Froude number (Fr), friction resistance only relative to Reynolds number (Re). Ship model and hydraulic model are usually on the basis of gravity similar principle (Fr equal number), residual resistance part similar of prototype and model. Under gravity similar condition, ship model have to satisfy Re similar also, because Re of model is always less than actual ship, results to different maneuverability, this behavior is defined as maneuverability scale effect. In order to ensure maneuverability similar, ship model is need to be corrected scale effect. At present, the common method of scale effect correction is reducing push wheel edges rudder area, correct rudder effect.

First is 9 barges and 3 barges ship model $Z$ shape calibration test (100\% rudder area).In the research work of china inland channel and across buildings standard ship model test, it is put forward that $\mathrm{T}^{\prime}$ error margin between ship model and actual is no more than $5 \%, K^{\prime}$ is no more than actual ship $80 \%[3,4]$. The test result shows that 9 barges and 3 barges ship model (100\% AR) T' are respectively reduce $11.98 \%$ and $8.20 \%$ relative to actual ship, all exceed $5 \%$, ship model scale effect is obvious, which is need to be corrected.

According to result analysis of original rudder ship model maneuverability calibration test, appropriate negative correction to ship model original rudder. Determined by comprehensive analysis, we can reduce $20 \%$ of full rudder area, which is on the basis of actual ship maneuverability calibration procedures, for 9 barges and 3 barges ship model Z shape calibration test. Comparing with 100\% AR (Fig.4), test result of reduce $20 \%$ rudder area ( $80 \%$ AR) (Fig.2, Fig.3) showed that, T' has a significant increase, $K$ ' is just a small decrease. When pushing wheel edges rudder area is reduced, gyration moment of rudder is decreasing, $\mathrm{K}^{\prime}$ is decreasing. Meanwhile, caudal role of rudder has been weaken; gyration moment of resistance $\mathrm{N}$ is decreasing, $\mathrm{K}$ ' has been weaken, so $\mathrm{K}^{\prime}$ is just a small decrease. When rudder area is reduced, gyration damping moment $\mathrm{N}$ of ship model is decreasing, gyration moment of inertia I is not changed, so T' has a significant increase when rudder area is decreased. In this calibration test, with rudder area changing, trends of K' and T' is reasonable. Ship model of 9 barges and 3 barges are corrected, $K$ ' is respectively to be $10.97 \%$ and $13.63 \%$ smaller than actual ship, $\mathrm{T}^{\prime}$ is respectively to be $0.94 \%$ and $3.02 \%$ larger than actual ship. Compare with actual ship, error of ' $\mathrm{T}$ ' is no more than $5 \%, \mathrm{~K}$ ' is no less than $80 \%$.It shows that ship model maneuverability can satisfy navigation conditions of test after corrected.

(a)

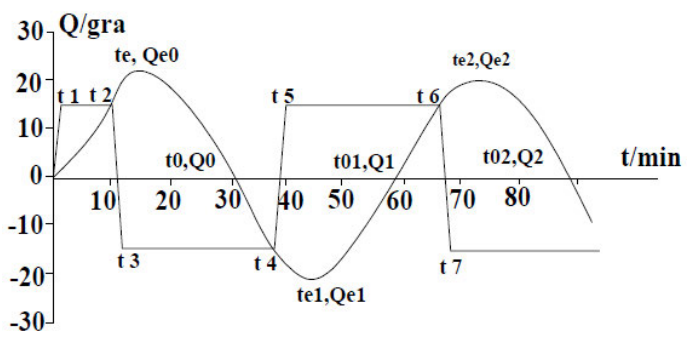

(b)

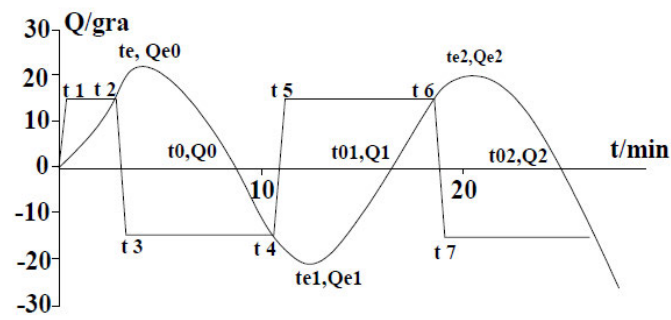

Fig. 2. Various ship model fleets with a scale 1:100 $15^{\circ} \mathrm{Z}$ shape test $(80 \% \mathrm{AR}$, $H=5 \mathrm{~m})($ a. 9 barges fleet; $b .3$ barges fleet $)$ 
(a)

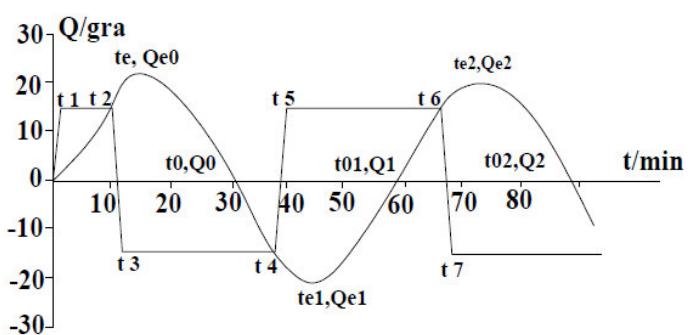

(b)

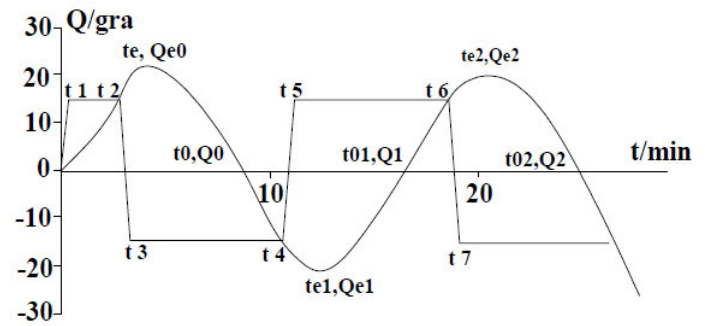

Fig. 3. Various ship model fleet with a scale $1: 10015^{\circ} \mathrm{Z}$ shape test $(80 \% \mathrm{AR}$, $H=5 \mathrm{~m})(a .9$ barges fleet; $b .3$ barges fleet $)$

(a)

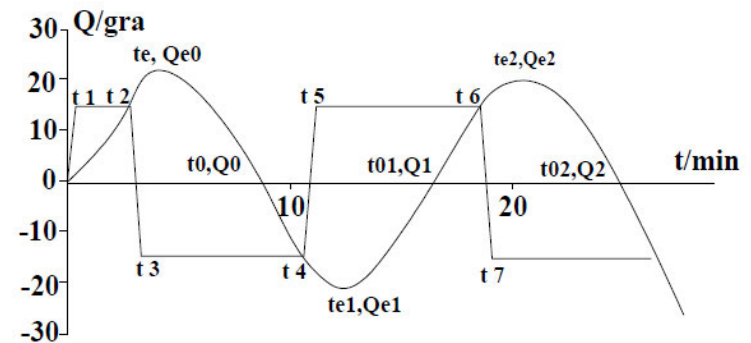

(b)

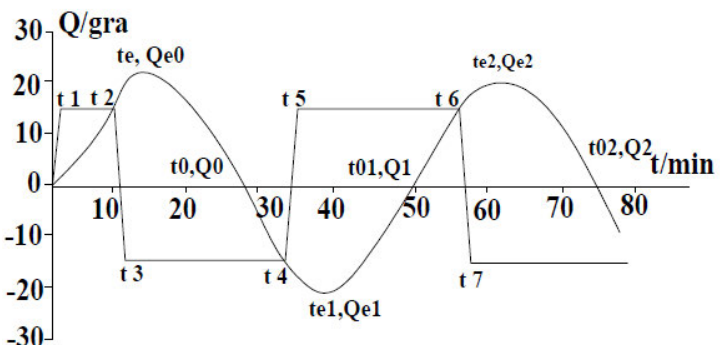

Fig. 4. Various ship model fleets with a scale 1:100 $15^{\circ} \mathrm{Z}$ shape test (100\% AR) (a. 9 barges fleet; $b .3$ barges fleet)
The analysis of ship test data is on the basis of large ship model simulated computation result, which is put forward in the research of Three Gorges Project standard navigation maneuverability motion mathematic model and correlation technology. Test computation result (Tab.3) showed that, shallow water ship model test $(\mathrm{H}=5 \mathrm{~m})$, compare with $\mathrm{H}=\infty$, hydrostatic navigation speed is lower, $\mathrm{K}^{\prime}, \mathrm{T}$ ' increase, the trends is in line with simulated computation results. According to various numerical values, the change direction of ship model speed is similar to simulated computation speed of 9 barges ship fleet. Ship model test $(\mathrm{H}=5 \mathrm{~m})$ compares with test $(\mathrm{H}=\infty$, $80 \%$ AR), K', T' and simulated computation are at a similar change rate, T' is slightly bigger. After corrected, 9 barges model $(80 \% \mathrm{AR})$ at $\mathrm{H}=5 \mathrm{~cm}$ (equal to actual ship $\mathrm{H}=5 \mathrm{~m}$ ), compares with $\mathrm{K}$, $\mathrm{T}^{\prime}$ of $\mathrm{Z}$ shape test simulated computation ( $\mathrm{H}=5 \mathrm{~m}, 15^{\circ}$ rudder angle), it is basically satisfied that error of T' which is no more than $5 \%$ and $\mathrm{K}^{\prime}$ is no less than $80 \%$. T' is slightly bigger and it is safe for actual ship.

\section{CONCLUSIONS}

The maneuverability calibration result was based on ship model of 3 barges and 9 barges $Z$ shape test with a scale 1:100, showed that every fleet maneuverability index K', T' is corrected, in agreement with changing regularity of scale and rudder area as a function of actual ship, the trends is reasonable. The dispersion of ship model calibration test result is smaller, stable and reliable. The changing trends and numerical value of ship model shallow water K', T' is in accordance with actual ship simulated computation, meet the requirements of approximate to actual ship and actual ship security. It showed that ship model maneuverability can satisfy navigation conditions of test after rudder area corrected, and have the maneuverability feature of actual ship. Result is safe.

The findings of this paper may significantly facilitate the shallow-water maneuverability calibration of navigation ship fleets.

Tab. 3. Ship model shallow water $Z$ shape test $\left(H=5 m, 15^{\circ}\right)$ result compared

\begin{tabular}{|c|c|c|c|c|c|c|c|c|}
\hline \multirow[b]{2}{*}{ Depth } & \multirow{2}{*}{\multicolumn{2}{|c|}{ Fleet }} & \multirow{3}{*}{$\begin{array}{c}\begin{array}{c}\text { Rudder } \\
\text { Area }(\%)\end{array} \\
100 \\
\end{array}$} & \multicolumn{2}{|c|}{$\mathrm{K}^{\prime}$} & \multicolumn{2}{|c|}{$\mathrm{T}^{\prime}$} & \multirow[b]{2}{*}{$\begin{array}{l}\text { Speed } \\
(\mathrm{m} / \mathrm{s})\end{array}$} \\
\hline & & & & $\begin{array}{c}\text { Numerical } \\
\text { Value }\end{array}$ & $\begin{array}{c}\text { Error } \\
(\%)\end{array}$ & $\begin{array}{c}\text { Numerical } \\
\text { Value }\end{array}$ & $\begin{array}{c}\text { Error } \\
(\%)\end{array}$ & \\
\hline \multirow{5}{*}{$\mathrm{H}=\infty$} & \multirow{2}{*}{ Actual Ship } & 9 Barges & & 1.540 & & 0.640 & & 3.155 \\
\hline & & 3 Barges & 100 & 1.680 & & 0.695 & & 4.289 \\
\hline & \multirow{2}{*}{ Ship Model } & 9 Barges & 80 & 1.371 & -10.97 & 0.646 & +0.94 & 0.3155 \\
\hline & & 3 Barges & 80 & 1.451 & -13.63 & 0.716 & $\begin{array}{l}+3.02 \\
\end{array}$ & 0.4289 \\
\hline & $\begin{array}{c}\text { Simulated } \\
\text { Computation }\end{array}$ & 9 Barges & 100 & 1.487 & & 0.657 & & 3.155 \\
\hline \multirow{2}{*}{$\mathrm{H}=5 \mathrm{~cm}$} & \multirow{2}{*}{ Ship Model } & 9 Barges & 80 & 1.598 & -10.22 & 0.995 & +5.73 & 0.2617 \\
\hline & & 3 Barges & 80 & 1.891 & & 1.067 & & 0.3450 \\
\hline $\mathrm{H}=5 \mathrm{~m}$ & $\begin{array}{l}\text { Simulated } \\
\text { Computation }\end{array}$ & 9 Barges & 100 & 1.780 & & 0.938 & & 2.606 \\
\hline
\end{tabular}




\section{ACKNOWLEDGEMENTS}

The first author would like to thank the help of testing ground for faculty members at Chongqing Jiaotong University. This study is subsidized by National Natural Science Foundation of China (59453600).

\section{REFERENCES}

1. Cai, C ."The development of J G II-V3.0 general software in Three Gorge pivot ship model experiment". Journal of Chongqing Jiaotong University. Vol 20, No 2, pp110115,2001.(in Chinese)

2. Cai, R-Z. "The Experimental studies on small ship model serviceability calibration and serviceability in shallow water in Three Gorges Project". Southwest Research Institute for Water Transport Engineering. Vol 3, No 8, pp 10-15,1996. (in Chinese)

3. Cai, R-Z."The experimental studies on small ship model serviceability calibration and serviceability in shallow water in Three Gorges Project's applied fundamental Research". Beijing: Press of University of Science and Technology of China. Vol 2, No 5, pp 88-90,1997. (in Chinese)

4. Jiang, Y-Q, Duan, Y-L, and Liu, R-X. "An unstructuredmesh MATLAB generator and numerical simulation of shallow water problems". Journal of Hydrodynamics. Vol 5, No 3, pp 56-59,2009. (in Chinese)

5. Katsuro K. "On the Maneuvering Performance of a Ship with the Parameter of Loading Condition.” SNAJ, Vol 12, No 168, pp 112-130,1990.

6. Muk, CO, Salina, CC, Arthur, TB, Edmond, YM, and Soon KT. "Simulating ship maneuvers in deep and coastal waters." Journal of ship research, Vol 51, No 3, pp 204-216,2007.

7. Sheng, Z-B, and Liu, Y-Z. "Principle of naval architecture". Shanghai Jiaotong University Press, Vol 11, No 6, pp 123126,2004. (in Chinese)

8. Su, X-Q. Ship maneuverability. National Defense Industry Press,1995.(in Chinese)

\section{CONTACT WITH THE AUTHOR}

\author{
Chuang Cai \\ Xinyong Cai \\ Yi Li
}

School of River and Ocean Engineering

Chongqing Jiaotong University

ul. Xuefu Avenue No.66 Chongqing

tel.: +8657 62652770, fax: +865762650204

\section{CHINA}

